http://sciforum.net/conference/ece-1

Conference Proceedings Paper - Energies ,, Whither Energy Conversion? Present Trends, Current Problems and Realistic Future Solutions",

\title{
Selection of Solar Collectors Technology and Surface for a Desiccant Cooling System based on Energy, Environmental and Economic Analysis
}

\section{Giovanni Angrisani*, Carlo Roselli, Maurizio Sasso, Francesco Tariello}

DING, Department of Engineering, Università degli Studi del Sannio, Piazza Roma 21, 82100 Benevento, Italy; E-Mails: giovanni.angrisani@unisannio.it; carlo.roselli@unisannio.it; sasso@unisannio.it

* Author to whom correspondence should be addressed; E-Mail: giovanni.angrisani@ unisannio.it; Tel.: +39-0824-305576; Fax: +39-0824-325246.

Received: 15 January 2014 / Accepted: 8 March 2014 / Published: 14 March 2014

\begin{abstract}
Desiccant-based air handling units can achieve reductions in greenhouse gas emissions and energy savings with respect to conventional air conditioning systems. Benefits are maximized when they interact with renewable energy technologies, such as solar collectors. In this work, experimental tests and data derived from scientific and technical literature are used to implement a model of a solar desiccant cooling system, considering three different solar collector technologies (air, flat plate and evacuated collectors). Simulations were then performed to compare the energy, environmental and economic performance of the system with those of a desiccant-based unit in which regeneration thermal energy is supplied by a natural gas boiler, and with a conventional air handling device. The only solution that allows to achieve the economic feasibility of the solar desiccant cooling unit consists of $16 \mathrm{~m}^{2}$ of evacuated solar collectors. This solution allows to obtain, with respect to the reference system, a reduction of primary energy consumption and of the equivalent $\mathrm{CO}_{2}$ emissions of $50.2 \%$ and $49.8 \%$, respectively, with a pay-back time of 17 years.
\end{abstract}

Keywords: Desiccant cooling; solar energy; energy, environmental and economic analysis 
Desiccant cooling systems (DCS) are an interesting alternative to conventional cooling-based air conditioning systems with electrically-driven vapor compression cooling units, as they allow a more accurate humidity control, a better indoor air quality, a significant reduction in $\mathrm{CO}_{2}$ emissions, primary energy and electricity savings, [1]. Energy and environmental savings are maximized when desiccant cooling systems interact with renewable energy technologies, such as solar collectors or ground source heat pumps. Therefore, desiccant-based systems can significantly increase the penetration of renewable energy sources in both developing and industrialized countries.

Solar energy use for space cooling requirements (solar cooling) is highly desirable, as its availability coincides with the cooling demand; therefore, summer peak demand of electricity due to extensive use of electric air conditioners, that matches with the peak solar irradiance, can be lowered.

Several experimental and simulative analysis were carried out to compare the performance of solar desiccant and conventional cooling systems. A numerical and experimental study of a solar assisted desiccant cooling system for air conditioning applications in Pakistan was presented in [2]. Using sets of measured data, a validation of a numerical model of the cooling system was undertaken. Life cycle assessment of solar air collector was performed, and energy, environmental and economic payback periods were found to be equal to $1,1.5$ and 14 years, respectively.

In [3], a solar driven two-stage rotary desiccant cooling system and a vapor compression system were simulated to provide cooling for a commercial office building in two cities with different climates: Berlin and Shanghai. Compared to the vapor compression system, the desiccant cooling system had better air quality and consumed about $70-80 \%$ less electricity. The economic analysis demonstrated that the investment payback periods were 4.7 years in Berlin and 7.2 years in Shanghai.

In [4], a solar hybrid air-conditioning system was formulated, using evacuated tubes as solar collectors, adsorption refrigeration, chilled ceilings and desiccant dehumidification. The year-round performances of the proposed solar hybrid air-conditioning systems were evaluated for two typical office types. The solar hybrid air-conditioning system was compared with the conventional vapor compression refrigeration system. The proposed solar hybrid air-conditioning system was technically feasible when interacting with high temperature cooling (chilled ceilings). In fact, the yearly primary energy consumption of the hybrid system is about $20-40 \%$ lower than that of the conventional chillers.

In [5], a desiccant-based air handling unit (AHU) was coupled with a novel CPVT (Concentrating Photovoltaic/Thermal), consisting of a parabolic trough concentrator and a linear triangular receiver. A TRNSYS project was developed. Electricity produced by the CPVT collector is used to power the auxiliaries of the AHU, the chiller and the electric load of users, while thermal energy is used to heat the regeneration air flow during the summer period and the process air in winter. Surplus electricity is sold to the grid, whereas surplus thermal energy is used for domestic hot water (DHW) production. Integrations are provided by the electric grid and by a gas-fired boiler. On an annual basis, the analyzed system obtains a primary energy saving in the range $81-89 \%$ and avoided equivalent $\mathrm{CO}_{2}$ emissions in the range $85-91 \%$, depending on the DHW required, with respect to a reference case.

In [6], a detailed analysis of the energy and economic performance of desiccant cooling systems equipped with both single glazed standard air and hybrid photovoltaic/thermal (PVT) collectors for applications in hot and humid climates was presented. System performance was investigated through hourly simulations for different systems and load combinations. Moreover, three configurations of solar-assisted AHU equipped with desiccant wheels were considered and compared with standard 
AHUs, focusing on achievable primary energy savings. Sensitivity analysis was performed for different solar collector areas. The cost of conserved energy and the payback time were calculated, with and without public incentives for solar cooling systems. An outcome of this work was that systems equipped with PVT collectors have better performance in terms of primary energy saving than conventional systems fed by vapour compression chillers and coupled with PV cells. The economics of these systems are acceptable, but they become more interesting in the case of public incentives of up to $30 \%$ of the investment cost (Simple Payback Time from 5 to 10 years) and doubled energy prices.

In this paper, different types of solar thermal collectors are investigated for the same desiccantbased AHU, in order to assess the most suitable technology. In this paper, the experimentally calibrated and validated model of an air-conditioning unit based on a desiccant wheel is simulated, analyzing the interaction with three types of collectors (air, flat-plate and evacuated) and with a conventional thermal generation device (boiler), and compared, by means of energy, environmental and economic analysis, with a conventional system.

\section{The user}

The desiccant-based AHU provides the air-conditioning service (activation schedule from Monday to Saturday, from 8:30 to 19:00) to a lecture room, with a floor area of $63.5 \mathrm{~m}^{2}, 30$ seats; to guarantee thermal comfort for occupants, indoor cooling set-point temperature equal to $26{ }^{\circ} \mathrm{C}$ and relative humidity set-point equal to $50 \%$ were set. The rates of heat gain from occupants were evaluated considering a "seated - very light writing" degree of activity, that determines a sensible and latent heat gain of $65 \mathrm{~W}$ and $55 \mathrm{~W}$ per person, respectively, as defined by standard UNI EN ISO 7730. Heat gain from artificial lighting was evaluated as $10 \mathrm{~W} / \mathrm{m}^{2}$. Infiltration rate was set to $0.6 \mathrm{~h}^{-1}$.

The dimensions and thermal insulation characteristics of the opaque and transparent components of the simulated building envelope, the models of the desiccant-based AHU components and of the storage tank can be found in [7, 8]. Furthermore, over the whole year, solar collectors provide thermal energy for DHW production, to a nearby user (a multifamily house). A tool to generate realistic DHW load profiles was used, as done in [7]. Each profile consists of a value of water flow rate for every time step. A requirement of 400 liters per day was assumed, corresponding to a multifamily house with 10 persons, considering an average requirement of $401 /($ person $\cdot$ day)

\section{The test facility}

At "Università degli Studi del Sannio", in Benevento (Southern Italy), a desiccant-based AHU coupled to an electric chiller and a natural gas-fired boiler (Fig. 1), is currently experimentally analyzed. Nominal characteristics of the devices are the following:

- air-cooled water chiller: $8.50 \mathrm{~kW}$ cooling capacity, $\mathrm{COP}=3.00$;

- boiler: $24.1 \mathrm{~kW}$ thermal power, $90.2 \%$ nominal efficiency;

- storage tank: made of carbon steel, with a capacity of 10001 and a net storage volume of 8551 . It has three internal heat exchangers (IHE): two of them can interact with external energy conversion devices; the third one can be used for domestic hot water production. The tank is insulated with a 100 $\mathrm{mm}$ thick layer of polyurethane with thermal conductivity of $0.038 \mathrm{~W} / \mathrm{mK}$. 
- desiccant wheel (DW): filled with silica-gel, a desiccant material that can be regenerated at temperatures as low as $60-70{ }^{\circ} \mathrm{C}$. The DW has a weight of $50 \mathrm{~kg}$ and its dimensions are $700 \mathrm{~mm} \times 200$ $\mathrm{mm}$ (diameter $\mathrm{x}$ thickness). $60 \%$ of the rotor area is crossed by the process air, while the remaining $40 \%$ by the regeneration air. The nominal rotational speed of the DW is 12 revolutions per hour.

The AHU is crossed by three outdoor air streams, each with a flow rate of $800 \mathrm{~m}^{3} / \mathrm{h}$ :

- process air, dehumidified by the desiccant wheel (1-2), pre-cooled by the cooling air stream in an air-to-air cross flow heat exchanger (2-3), finally cooled to the supply temperature by a cooling coil interacting with the chiller (3-4);

- regeneration air, heated by the heating coil interacting with the boiler or the storage tank (1-5); it is used to regenerate the desiccant wheel (5-6);

- cooling air, cooled by a humidifier (1-7) and then used to pre-cool the process air exiting the desiccant wheel (7-8).

A solar collectors field is planned to be installed and connected to the lower IHE of the storage tank; in this work, the solar circuit and control is analyzed by simulation.

Hot water is drawn from the upper side of the tank, to heat the regeneration air flow up to the required regeneration temperature, in the heating coil $(\mathrm{HC})$ of the regeneration air duct. If the water temperature at the outlet of the storage tank (sensor TTW20 in Fig. 1) is not enough to achieve the required regeneration air temperature (sensor TA5), the boiler intervenes providing further thermal energy. The solar pump activates when the water temperature at the outlet of the collectors is higher than the storage tank temperature (sensor TTW26).

As regards the domestic hot water requirements, DHW is drawn at the exit of the IHE3 (Fig.1). If the outlet water temperature (sensor TTW22 in Fig. 1) is higher than the set-point value (DHW is supplied to the user at $45{ }^{\circ} \mathrm{C}$ ), a three-way valve operates so that the right amount of mains water bypasses the tank and mixes with the hot fluid exiting the storage. If the outlet water temperature is lower than $45^{\circ} \mathrm{C}$, the boiler activates to provide further thermal energy to the storage tank.

The pumps of the boiler and the chiller have an electric consumption of $150 \mathrm{~W}$ each, while for the solar collectors pump an electric requirement of $100 \mathrm{~W}$ has been estimated. The process, regeneration and cooling air fans require $320 \mathrm{~W}$ each.

\section{Method}

Simulations were carried out to evaluate the performance of the previously described SDCS (solar DCS) providing the air-conditioning service to a lecture room. Four scenarios with reference to thermal energy source to regenerate the DW were considered: $A=$ air collectors, $B=$ flat-plate collectors, $\mathrm{C}=$ evacuated tube collectors, $\mathrm{D}=$ natural gas boiler.

Italian law does not specify the duration of the summer activation period for air-conditioning systems; therefore the AHU was assumed active from June 1st to September 15th.

In Fig. 2, the main energy flows of scenarios B and C, related to the air-conditioning system, are shown. The only difference for scenario A is the absence of the thermal storage tank.

Thermal energy coming from solar collectors $\left(E_{t h, S C}\right)$ is used, with partial integration from a natural gas boiler $\left(E_{t h, B}\right)$, for the regeneration of the desiccant rotor $\left(E_{t h, r e g}\right) . E_{p, B}$ is the primary energy input of the boiler; the heating coil has an effectiveness equal to $84.2 \%$, [8]. Electric energy for the auxiliaries 
$\left(E_{e l, a u x}\right)$ and the chiller $\left(E_{e l, c h i l}\right)$, that produces chilled water $\left(E_{c o, c h i l}\right)$ for the cooling coil (CC), is drawn from the electric grid. $E_{p, E G}$ is the primary energy input of the electric grid. Cooling energy is transferred from the chilled water to the process air in the $\mathrm{CC}\left(E_{c o, C C}\right)$. Finally, energy for space cooling purposes $\left(E_{c o, u s}\right)$ is provided to the building.

Figure 1. The layout of the desiccant-based AHU.

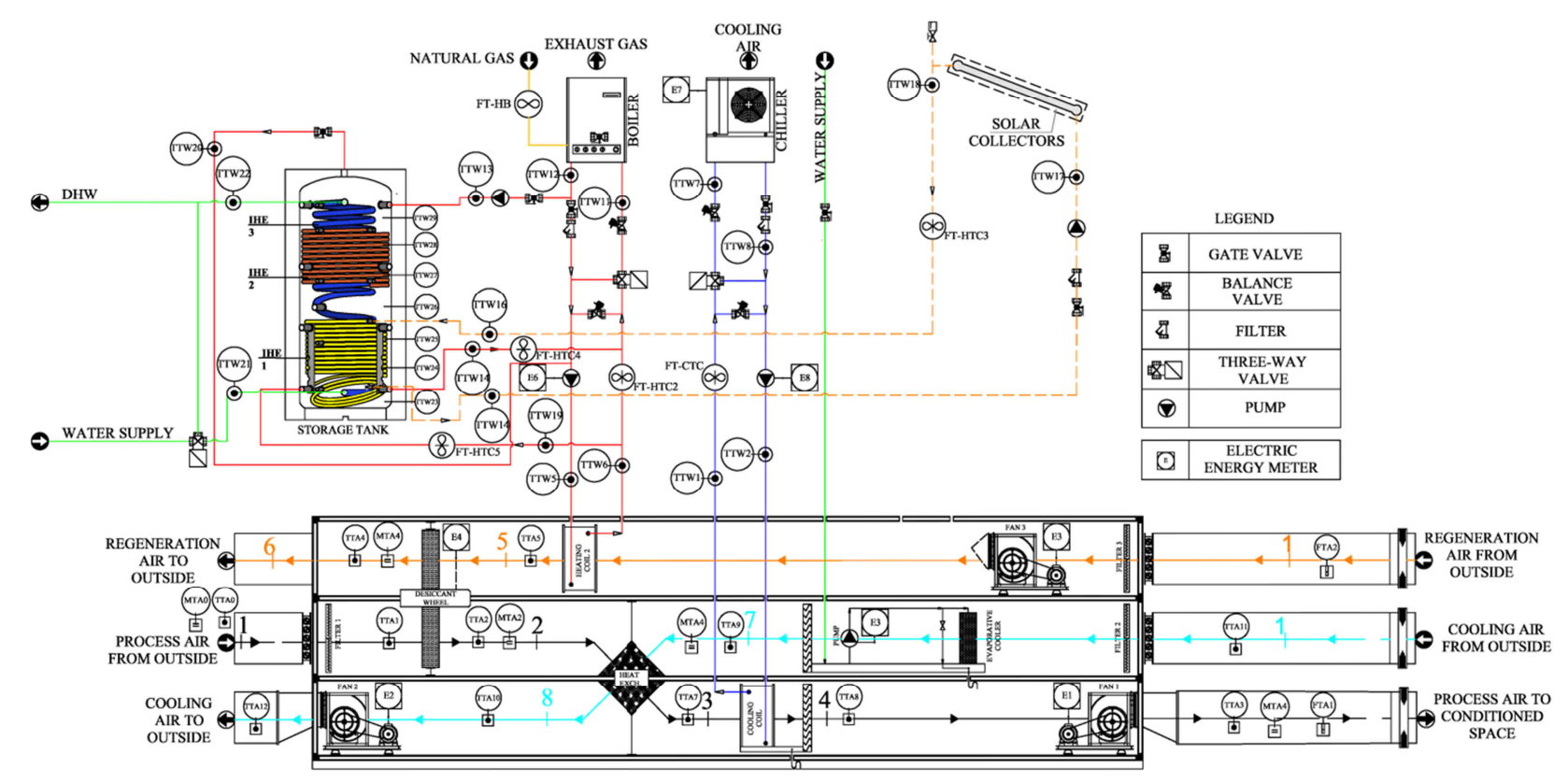

Through the year thermal energy coming from solar collectors and from the integration boiler is also used for DHW (only in scenarios B and C, air collectors cannot be used for DHW purposes). In scenarios A and D thermal energy for DHW purposes is provided by the natural gas boiler.

The four scenarios have been simulated and compared with a reference system, in terms of primary energy consumption, equivalent $\mathrm{CO}_{2}$ emissions and costs, by means of the commercial dynamic simulation software TRNSYS 17.1, expanded with the additional TESS (Thermal Energy System Specialists) libraries. The simulations were performed on an annual basis, with a time step of $0.5 \mathrm{~h}$.

To evaluate the performance of the systems, the climatic conditions of Naples (Italy) were taken into account with the corresponding climatic file.

The slope and the azimuth of the solar collectors surface was set to $20^{\circ}$ (to optimize the summer operation of collectors, when the sun is high in the sky) and $0^{\circ}$ (facing South), respectively, while the gross solar collectors surface was varied in the range $4-16 \mathrm{~m}^{2}$, with a $2 \mathrm{~m}^{2}$ step.

The building and the related cooling loads were simulated hour by hour with the interface "TRNBuild" of TRNSYS and its "type 56". In particular, depending on the hour-by-hour cooling load of the building, the supply humidity ratio and temperature of process air is evaluated; accordingly, the supply humidity ratio value is used as set-point for the desiccant wheel; then the desiccant wheel model calculates the regeneration air temperature required.

The corresponding thermal power related to DHW draw is evaluated considering the water mass flow rate, the specific heat capacity, the temperature of cold water from the mains entering the storage tank and the temperature of the hot water supplied to the end-user $\left(45^{\circ} \mathrm{C}\right)$. 
Figure 2. Energy flows during with active AHU (scenarios B and C).

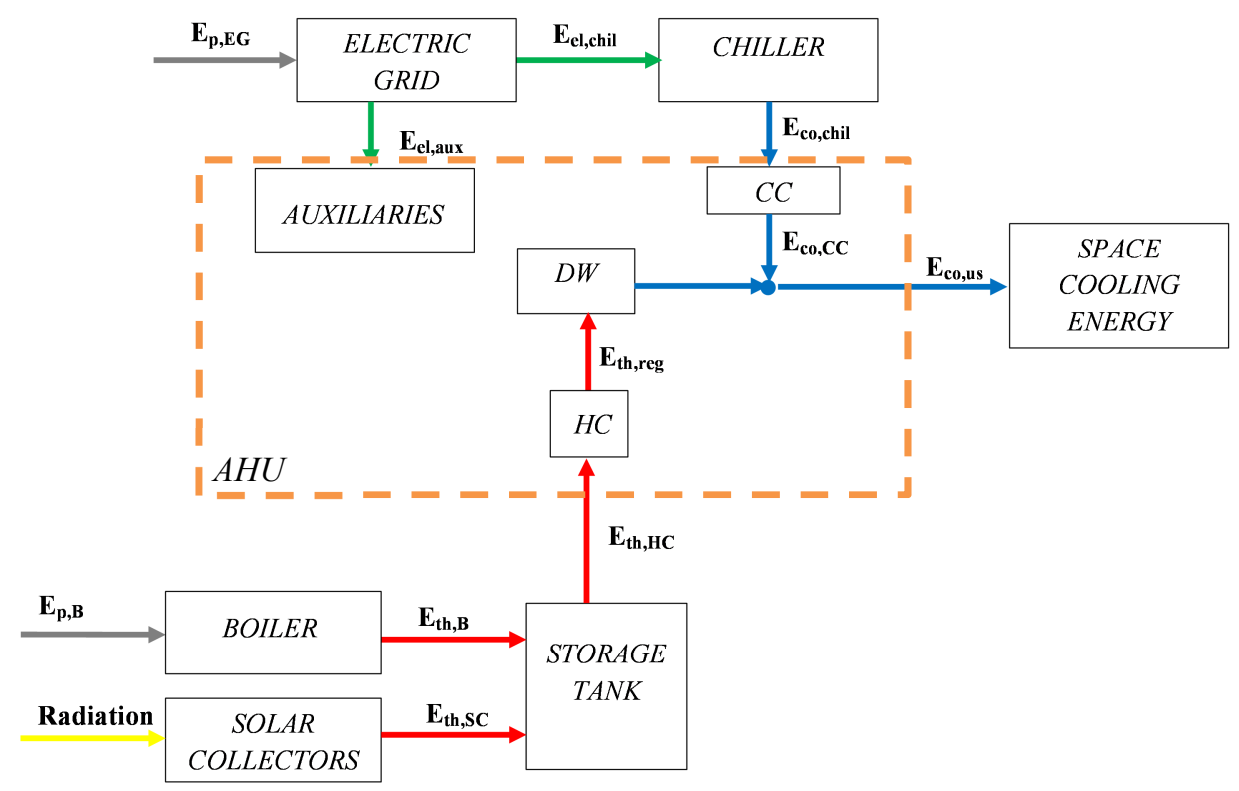

The chiller is simulated by means of a performance map based model that evaluates the performance (both at full and partial load), in terms of cooling capacity and COP as a function of chilled water and ambient air dry-bulb temperatures. In particular, the model relies on two external data files: the former contains the capacity ratio (ratio between cooling capacity at current conditions and its nominal value) and performance ratio (ratio between COP at current conditions and its nominal value) as a function of chilled water and ambient air dry-bulb temperatures; the latter contains the data about the fraction of full load power (ratio between electric power input at current conditions and its nominal value) as a function of PLR (partial load ratio, actual cooling capacity over its nominal value). Data provided by the manufacturer were used to simulate the performance of the chiller, in terms of variable cooling capacity and energy performance, [9].

\subsection{Scenario A}

In this scenario, the AHU layout is different from that of Fig. 1, as the regeneration air directly crosses the solar air collectors, and the storage tank is not present. In fact, these types of collectors use air instead of a liquid as heat transfer fluid, so they have the advantage to avoid any problems of corrosion, freezing and fluid losses in the circuit. On the other hand, they have a reduced efficiency with respect to flat-plate and evacuated collectors, due to low heat exchange convective coefficients between air and the absorber plate; furthermore, air collectors do not allow the storage of thermal energy. The model of air collectors is calibrated by means of data found in [10].

\subsection{Scenario B}

Solar radiation is collected by means of flat-plate collectors, that heat up a water/glycol mixture, which then transfers thermal energy to the fluid (water) in the storage tank, by means of the lower heat exchanger. Flat-plate collectors model is calibrated by means of manufacturer data found in [11]. 


\subsection{Scenario $C$}

This scenario is similar to the previous one, the only difference is that evacuated solar collectors are used instead of flat-plate ones. The collectors model is calibrated by means of manufacturer data, [12].

The main parameters of the simulated solar collectors are reported in Table 1.

Table 1. Models used for solar collectors simulation and their main parameters.

\begin{tabular}{|c|c|c|c|}
\hline Component & Main parameters & Value & Units \\
\hline \multirow{6}{*}{$\begin{array}{l}\text { Solar } \\
\text { air } \\
\text { collectors }\end{array}$} & Overall reflectance of the collector surface & 0.053 & - \\
\hline & Emissivity of the top and back surfaces of the collector & 0.85 & - \\
\hline & Emissivity of the top and bottom surface of the flow channel & 0.85 & - \\
\hline & Conductive resistance of the back insulation layer & 3.6 & $\mathrm{~m}^{2} \cdot \mathrm{K} / \mathrm{W}$ \\
\hline & Conductive resistance of the absorber plate and structural layer & 0.036 & $\mathrm{~m}^{2} \cdot \mathrm{K} / \mathrm{W}$ \\
\hline & Specific heat capacity of air & 1.007 & $\mathrm{~kJ} /(\mathrm{kg} \cdot \mathrm{K})$ \\
\hline \multirow{5}{*}{$\begin{array}{l}\text { Flat-plate } \\
\text { solar } \\
\text { collectors }\end{array}$} & Tested flow rate & 0.0213 & $\mathrm{~kg} /\left(\mathrm{s} \cdot \mathrm{m}^{2}\right)$ \\
\hline & Intercept efficiency & 0.712 & - \\
\hline & Efficiency slope & 3.53 & $\mathrm{~W} /\left(\mathrm{m}^{2} \cdot \mathrm{K}\right)$ \\
\hline & Efficiency curvature & 0.0086 & $\mathrm{~W} /\left(\mathrm{m}^{2} \cdot \mathrm{K}^{2}\right)$ \\
\hline & Fluid specific heat & 3.84 & $\mathrm{~kJ} /(\mathrm{kg} \cdot \mathrm{K})$ \\
\hline \multirow{5}{*}{$\begin{array}{l}\text { Evacuated } \\
\text { solar collectors }\end{array}$} & Tested flow rate & 0.0213 & $\mathrm{~kg} /\left(\mathrm{s} \cdot \mathrm{m}^{2}\right)$ \\
\hline & Intercept efficiency & 0.72 & - \\
\hline & Efficiency slope & 0.97 & $\mathrm{~W} /\left(\mathrm{m}^{2} \cdot \mathrm{K}\right)$ \\
\hline & Efficiency curvature & 0.0055 & $\mathrm{~W} /\left(\mathrm{m}^{2} \cdot \mathrm{K}^{2}\right)$ \\
\hline & Fluid specific heat & 3.84 & $\mathrm{~kJ} /(\mathrm{kg} \cdot \mathrm{K})$ \\
\hline
\end{tabular}

\subsection{Scenario D}

Thermal energy to regenerate the silica-gel rotor in the desiccant-based air handling unit is provided by a natural gas boiler (thermal efficiency equal to $82.8 \%$ ), directly interacting with the $\mathrm{HC}$ in the regeneration path of the AHU.

\subsection{Reference System (RS)}

During the activation period of the air-conditioning system, a conventional AHU operates to reach the same hour-by-hour supply condition of process air in the desiccant-based scenarios (state "4" in Fig. 1), starting from the same outdoor conditions (state "1" in Fig. 1) and with the same schedule. In particular, the process air is cooled below the dew point temperature and dehumidified by a cooling coil interacting with an electric compression chiller; subsequently, it is heated up to the same supply temperature of the desiccant-based AHU by a heating coil interacting with a natural gas boiler, that provides thermal energy for air post-heating $\left(E_{t h, p h}\right)$.

The conventional AHU is equipped with two pumps (one for the chiller and one for the boiler, 150 $\mathrm{W}$ each) and one fan (process air, $320 \mathrm{~W}$ ). 
Electric energy for the auxiliaries and the chiller, that produces chilled water for the cooling coil, is drawn from the electric grid. The chiller in the RS has to balance both the sensible and latent loads of process air, therefore it has a higher rated capacity $(16.3 \mathrm{~kW})$ and a lower rated COP $(2.72)$ than the one in the desiccant-based scenarios, that has to manage the sensible load only. Thermal energy for air post-heating and for DHW is provided by the natural gas boiler.

The energy performance parameters of the electric grid, the boiler, the heating and the cooling coils were assumed equal to the values in the scenarios A to D.

The energy performance of the desiccant-based systems is evaluated in terms of annual avoided primary energy consumption, defined as:

$$
E_{p, a v}=E_{p}^{R S}-E_{p}^{S D C S}
$$

where

$$
E_{p}^{S D C S}=\left(E_{e l, c h i l}+E_{e l, a u x}\right) / \eta_{E G}+E_{t h, B} / \eta_{B}
$$

is the primary energy required on an annual basis by the solar desiccant scenarios.

$E_{p}^{R S}$ represents primary energy consumption of the RS, that can be evaluated with an equation very similar to eq. 2 .

The environmental performance of the systems are evaluated in terms of avoided equivalent $\mathrm{CO}_{2}$ emissions:

$$
\mathrm{CO}_{2-e q, a v}=\mathrm{CO}_{2-e q}^{R S}-\mathrm{CO}_{2-e q}^{S D C S}
$$

where

$$
C O_{2-e q}^{S D C S}=\left(E_{e l, c h i l}+E_{e l, a u x}\right) \cdot \alpha+E_{t h, B} \cdot \beta / \eta_{B}
$$

are the equivalent $\mathrm{CO}_{2}$ emissions on an annual basis by the solar desiccant scenarios. A similar equation applies for $C \mathrm{O}_{2-e q}^{R S}$.

The previously described equations are general, however, the numerical values used for the parameters refer to the Italian situation. In particular:

- $\eta_{E G}$ is the average energy performance factor of Italian reference system for electricity supply, including transmission and distribution losses (ratio of electric energy output to primary energy input), assumed equal to $42.0 \%$ [7],

- $\eta_{B}$ is thermal efficiency of the boiler (equal to $82.8 \%$, average value derived from experimental tests);

- $\alpha$ is the specific equivalent $\mathrm{CO}_{2}$ emission factor of electricity drawn from the grid $\left(0.573 \mathrm{~kg} / \mathrm{kWh}_{\mathrm{el}}\right.$, [7]);

- $\beta$ is the specific equivalent $\mathrm{CO}_{2}$ emission emission factor for primary energy related to natural gas consumption $(0.207 \mathrm{~kg} / \mathrm{kWh}$, [7]);

- LHV (lower heating value) of natural gas equal to $9.52 \mathrm{kWh} / \mathrm{Nm}^{3}$;

- unitary cost of natural gas $\left(c_{N G}\right)$ in the range $0.612-0.964 € / \mathrm{Nm}^{3}$, depending on the annual consumption and assuming a non-domestic application, e.g. an office;

- unitary cost of electricity $\left(c_{e l}\right)$ equal to $0.221 € / \mathrm{kWh}$;

- major cost of desiccant-based AHU with respect to conventional one is $10,000 €$;

- investment cost of storage tank equal to 3,000 €;

- investment cost of chiller: $3000 €$ for the SDCSs, $6000 €$ for the RS. 
- specific cost of collectors: $275 € / \mathrm{m}^{2}$ for air collectors; $360 € / \mathrm{m}^{2}$ for flat-plate collectors; $602 € / \mathrm{m}^{2}$ for evacuated collectors.

Furthermore, the Italian legislation recently introduced a mechanism to incentivize the use of renewable energy-based technologies to produce thermal energy [13]. In the case of solar collectors, the annual incentive can be evaluated as:

$$
I_{a, t o t}=C \cdot S
$$

where $I_{a, t o t}$ is the annual economic incentive, $C$ is a valorization coefficient depending on the type of plant (equal to $255 € / \mathrm{m}^{2}$ for solar cooling systems) and $S$ is the gross solar collectors area. The incentive is not considered for air collectors.

The economic feasibility of the SDCS is evaluated by means of the Simple Pay Back $(S P B)$ parameter, that evaluates the pay-back period of an investment, defined as:

$$
S P B=E C /\left(O C^{R S}-O C^{S D C S}\right)
$$

where $E C$ is the extra cost of the SDCS with respect to the RS. $O C^{S D C S}$ and $O C^{R S}$ are the operating costs of the solar desiccant cooling and reference systems:

$$
O C^{S D C S}=\left(E_{e l, c h i l}+E_{e l, a u x}\right) \cdot c_{e l}+E_{t h, B} \cdot c_{N G} /\left(\eta_{B} \cdot L H V\right)-I_{a, t o t}
$$

$O C^{R S}$ can be evaluated with an equation very similar to eq. 7 , obviously no incentives are included.

\section{Results and discussion}

The regeneration of the desiccant rotor requires $7.69 \mathrm{MWh} / \mathrm{y}$ of thermal energy, while thermal energy for DHW is $4.58 \mathrm{MWh} / \mathrm{y}$. In Tab. 2, the contribution of solar collectors and of the integration boiler to the overall thermal energy requirement (Fig. 2) as well as the annual solar fraction (SF) is shown for the three solar-based scenarios. SF is the ratio between the useful thermal energy coming from solar collectors and the total thermal energy need. Thermal energy for DW regeneration in scenario D and for DHW in both scenario D and RS are fully provided by the natural gas boiler.

The storage (scenarios B and C) determines thermal energy losses of about $12 \%$ on an annual basis.

Table 2. Thermal energy supplied by solar collectors and natural gas boiler.

\begin{tabular}{cccccccccccc}
\hline & \multicolumn{3}{c}{ Scenario A } & \multicolumn{3}{c}{ Scenario B } & \multicolumn{3}{c}{ Scenario C } \\
\hline $\begin{array}{c}\text { Gross surface } \\
{\left[\mathrm{m}^{2}\right]}\end{array}$ & $\mathrm{E}_{\mathrm{th}, \mathrm{SC}}$ & $\mathrm{E}_{\mathrm{th}, \mathrm{B}}$ & $\mathrm{SF}$ & \multicolumn{2}{c}{$\mathrm{E}_{\mathrm{th}, \mathrm{SC}}$} & $\mathrm{E}_{\mathrm{th}, \mathrm{B}}$ & $\mathrm{SF}$ & $\mathrm{E}_{\mathrm{th}, \mathrm{SC}}$ & $\mathrm{E}_{\mathrm{th}, \mathrm{B}}$ & $\mathrm{SF}$ \\
{$[\mathrm{MWh} / \mathrm{y}]$} & {$[-]$} & {$[\mathrm{MWh} / \mathrm{y}]$} & {$[-]$} & {$[\mathrm{MWh} / \mathrm{y}]$} & {$[-]$} \\
\hline 4 & 1.19 & 12.3 & 0.088 & 2.76 & 10.6 & 0.207 & 3.16 & 10.2 & 0.237 \\
6 & 1.72 & 11.7 & 0.128 & 4.03 & 9.22 & 0.304 & 4.72 & 8.46 & 0.358 \\
8 & 2.19 & 11.1 & 0.165 & 5.23 & 7.87 & 0.399 & 6.23 & 6.76 & 0.480 \\
10 & 2.64 & 10.6 & 0.199 & 6.35 & 6.62 & 0.490 & 7.70 & 5.13 & 0.600 \\
12 & 3.03 & 10.1 & 0.231 & 7.45 & 5.40 & 0.580 & 9.19 & 3.08 & 0.749 \\
14 & 3.36 & 9.72 & 0.257 & 8.45 & 4.28 & 0.664 & 10.6 & 1.84 & 0.852 \\
16 & 3.64 & 9.40 & 0.279 & 9.42 & 3.19 & 0.747 & 12.1 & 0.248 & 0.980 \\
\hline
\end{tabular}


In Tab. 3, the values of the other main energy flows (Fig. 2) are reported.

From the building simulation, the annual space cooling demand $\left(\mathrm{E}_{\mathrm{co}, \mathrm{us}}\right)$ is $3.64 \mathrm{MWh} / \mathrm{y}$. Cooling energy transferred from the chilled water to the process air $\left(\mathrm{E}_{\mathrm{co}, \mathrm{CC}}\right)$ is $2.50 \mathrm{MWh} / \mathrm{y}$, therefore about $68.7 \%$ of cooling energy is provided by the cooling coil interacting with the chiller, and about $31.3 \%$ is provided by the desiccant system. The electric chiller in the desiccant-based scenarios requires 1.04 $\mathrm{MWh} / \mathrm{y}$ of electricity, while the one in the RS has a higher electricity consumption $(2.28 \mathrm{MWh} / \mathrm{y})$.

Electricity requirement of auxiliaries in the SDCS is higher than that of the RS, due to higher electric power required by the auxiliaries of the desiccant-based AHU, and to the presence of the solar collectors pump in scenarios B and C.

In Fig. 3, the annual avoided consumption of primary energy, in terms of fossil fuels, with respect to the RS, is shown as a function of the installed gross collectors surface, for the three solar-based scenarios. Energy performance rises with the solar surface and they are higher with evacuated collectors (scenario C), then they reduce more and more with flat-plate collectors (scenario B) and air collectors (scenario A). The avoided primary energy consumption becomes positive for scenario $\mathrm{C}$ and B only beyond a certain value of the surface (about 9 and $11 \mathrm{~m}^{2}$, respectively), while this never happens with air collectors (scenario A). Scenario D has an higher primary energy consumption (about 8.91 MWh/y more) with respect to the RS.

In Fig. 4, the annual avoided emissions in the solar-based scenarios, with respect to the RS, are shown as a function of the installed gross collector surface. The same considerations done for Fig. 3 can be repeated, the only difference is the value of the collectors surface needed to achieve an environmental benefit, slightly lower than that obtained with the energy analysis (about 6.5 and $8.0 \mathrm{~m}^{2}$, in scenarios $\mathrm{C}$ and $\mathrm{B}$, respectively). Higher greenhouse gas emissions with respect to the RS are achieved by Scenarios A and D (about 1.64 t/y more).

Table 3. Main energy flows of the investigated scenarios.

\begin{tabular}{cccccc}
\hline & Scenario & Scenario & Scenario & Scenario & Reference \\
& $\mathrm{A}$ & $\mathrm{B}$ & $\mathrm{C}$ & $\mathrm{D}$ & system \\
\hline $\mathrm{E}_{\mathrm{co}, \text { us }}[\mathrm{MWh} / \mathrm{y}]$ & 3.64 & 3.64 & 3.64 & 3.64 & 3.64 \\
$\mathrm{E}_{\mathrm{co}, \mathrm{CC}}[\mathrm{MWh} / \mathrm{y}]$ & 2.50 & 2.50 & 2.50 & 2.50 & 4.94 \\
$\mathrm{E}_{\mathrm{co}, \text { chil }}[\mathrm{MWh} / \mathrm{y}]$ & 3.00 & 3.00 & 3.00 & 3.00 & 5.94 \\
$\mathrm{E}_{\mathrm{el}, \mathrm{chil}}[\mathrm{MWh} / \mathrm{y}]$ & 1.04 & 1.04 & 1.04 & 1.04 & 2.28 \\
$\mathrm{E}_{\mathrm{el}, \mathrm{aux}}[\mathrm{MWh} / \mathrm{y}]$ & 1.34 & 1.62 & 1.62 & 1.34 & 0.81 \\
$\mathrm{E}_{\mathrm{p}, \mathrm{EG}}[\mathrm{MWh} / \mathrm{y}]$ & 5.55 & 6.21 & 6.21 & 5.55 & 7.31 \\
$\mathrm{E}_{\text {th,ph }}[\mathrm{MWh} / \mathrm{y}]$ & - & - & - & - & 0.29 \\
\hline
\end{tabular}

The economic analysis states that the $E C$ of the SDCS with respect to the RS is never recovered in scenarios A, B and D; for the case with evacuated collectors (scenario C), the economic feasibility is achieved only with $16 \mathrm{~m}^{2}$ of solar surface, that provide a SPB of about 17 years for the overall SDCS.

In the final selection process, scenario $\mathrm{D}$ is discarded, due to the lower techno-economic performance with respect to the RS; air collectors is excluded as well, due to the low energy and 
environmental performance, and to the fact that Italian legislation does not provide economic incentives for this type of collectors.

Figure 3. Annual avoided primary energy consumption.

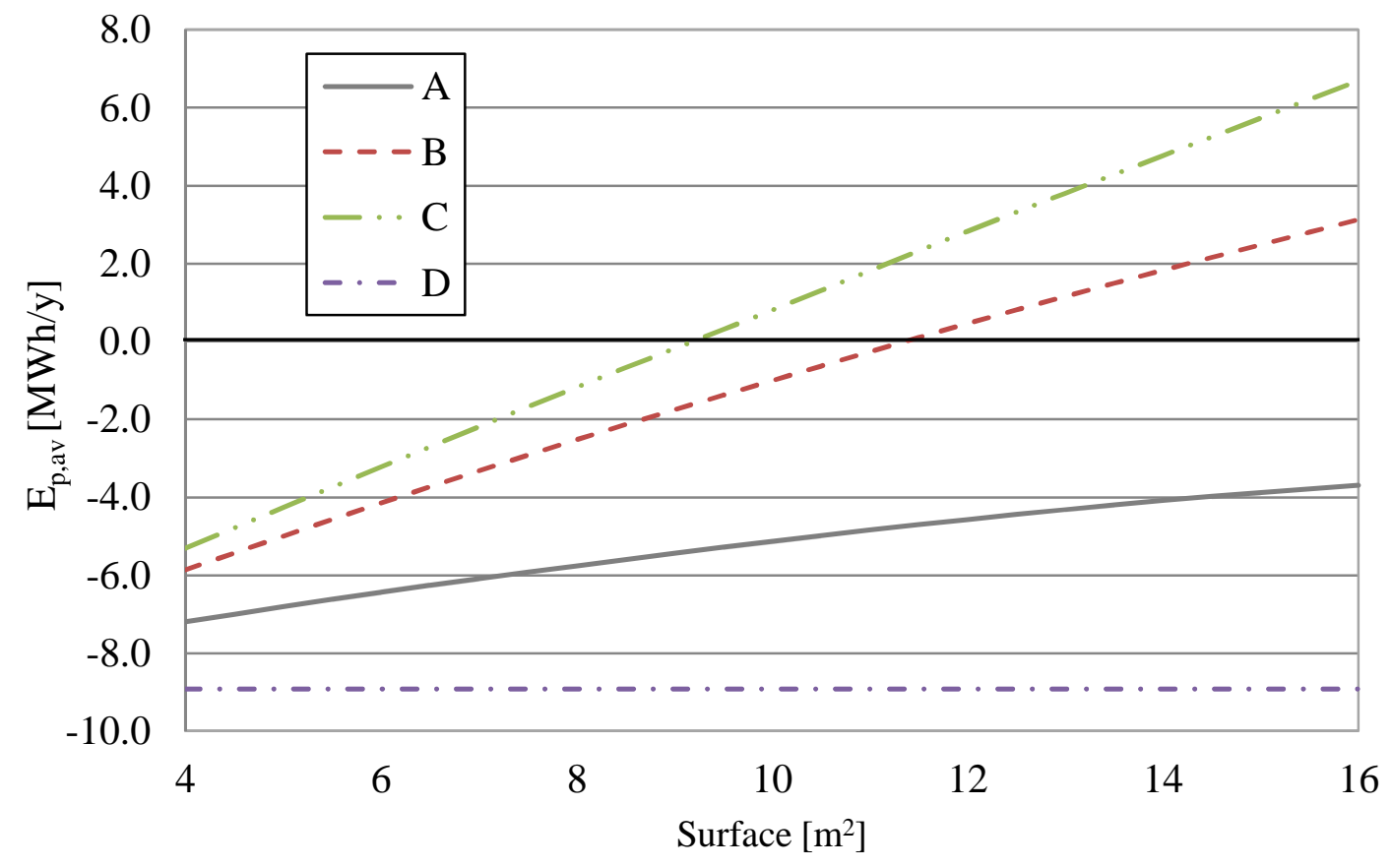

Figure 4. Annual avoided equivalent $\mathrm{CO}_{2}$ emissions.

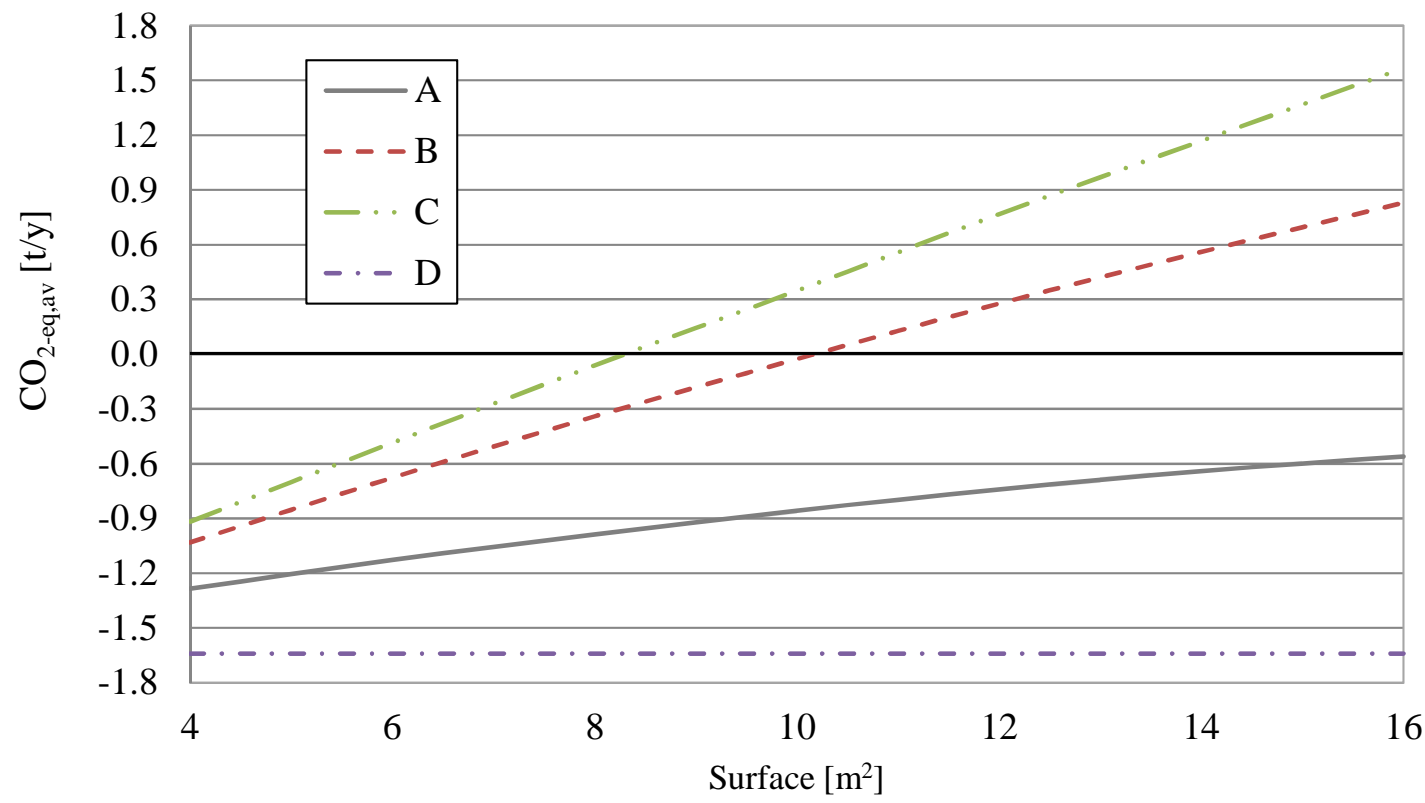

Given the small difference resulting from energy and environmental analysis between scenarios B and $\mathrm{C}$, a proper trade-off between technical performance and investment cost could be achieved selecting flat-plate collectors (scenario B), that is characterized by slightly lower energy and emissions savings with respect to evacuated collectors, but also by a smaller investment cost. However, the economic pay-back is not achieved in scenario $\mathrm{B}$, therefore the final choice should be $16 \mathrm{~m}^{2}$ of 
evacuated collectors (scenario C). This case achieves an avoided primary energy consumption of 6.69 $\mathrm{MWh} / \mathrm{y}$ (a reduction of 50.2\% with respect to the RS), avoided equivalent $\mathrm{CO}_{2}$ emissions of $1.57 \mathrm{t} / \mathrm{y}$ ($49.8 \%$ with respect to the RS), and a SPB of about 17 years, with an extra cost of about $19.6 \mathrm{k} €$.

A further possibility could be the installation of flat-plate collectors, but with a surface higher than $16 \mathrm{~m}^{2}$; in fact the economic analysis showed that the SPB reduces if the solar area is increased, for all types of collectors. Further analyses should be performed to investigate the energy, environmental and economic performance of the SDCS with installed surfaces higher than $16 \mathrm{~m}^{2}$.

\section{Conclusions}

In this paper, a model of a desiccant-based air handling unit, calibrated and validated by means of experimental data, was implemented in a commercial dynamic simulation software, to simulate its interaction with solar collectors to provide thermal energy for regeneration of the desiccant wheel. Four different scenarios, in terms of energy source for regeneration, were investigated: A - air collectors; B - flat-plate collectors; C - evacuated collectors; D - natural gas boiler. In the solar-based scenarios (A to $\mathrm{C}$ ), an integration with a natural gas boiler is also taken into account. The collectors models were calibrated by means of data derived from the technical and scientific literature.

Through the year, thermal energy coming from flat-plate and evacuated solar collectors is also used for domestic hot water preparation, that is provided by a natural gas boiler in scenario A and D.

These four scenarios were compared with a reference system, consisting of a conventional air handling unit, based on cooling dehumidification and post-heating, by means of an electric chiller and a natural gas boiler, respectively. The latter also provides thermal energy for DHW purposes. The comparison was based on an energy, environmental and economic analysis, investigating the effect of the installed gross solar surface.

As a final selection and dimensioning of the solar desiccant cooling system, the best solution could consist of $16 \mathrm{~m}^{2}$ of evacuated solar collectors. This solution allows to obtain, with respect to the reference system, a reduction of primary energy consumption and of the equivalent $\mathrm{CO}_{2}$ emissions of $50.2 \%$ and $49.8 \%$, respectively, and it is the only case achieving the economic pay-back of the investment, after about 17 years. This quite long pay-back period, despite the economic incentive related to the promoting mechanism introduced by Italian legislation, requires a reduction of the installation cost of solar desiccant cooling systems, mainly of the desiccant-based air handling unit, to benefit from the energy and environmental advantages of this type of systems.

\section{Conflicts of Interest}

The authors declare no conflict of interest.

\section{Nomenclature}

$\begin{array}{lll}\mathrm{c} & \text { unitary cost } & {\left[€ / \mathrm{Nm}^{3}\right] \text { or }[€ / \mathrm{kWh}]} \\ \mathrm{C} & \text { valorisation coefficient } & {\left[€ / \mathrm{m}^{2}\right]} \\ \mathrm{CO}_{2-\mathrm{eq}} & \text { equivalent } \mathrm{CO}_{2} \text { emissions } & {[\mathrm{t} / \mathrm{y}]} \\ \mathrm{COP} & \text { Coefficient Of Performance } & {[-]}\end{array}$




\begin{tabular}{|c|c|c|c|}
\hline E & energy & \multicolumn{2}{|c|}{ [MWh] } \\
\hline EC & extra cost & \multicolumn{2}{|l|}{ [€] } \\
\hline$I_{a, \text { tot }}$ & annual economic incentive & \multicolumn{2}{|l|}{$[€ / y]$} \\
\hline LHV & Lower Heating Value & \multicolumn{2}{|c|}{$\left[\mathrm{kWh} / \mathrm{Nm}^{3}\right]$} \\
\hline $\mathrm{OC}$ & operating cost & \multicolumn{2}{|l|}{$[€ / y]$} \\
\hline PLR & Partial Load Ratio & \multicolumn{2}{|l|}{$[-]$} \\
\hline $\mathrm{SF}$ & Solar Fraction & \multicolumn{2}{|l|}{$[-]$} \\
\hline $\mathrm{S}$ & gross solar collectors area & \multicolumn{2}{|l|}{$\left[\mathrm{m}^{2}\right]$} \\
\hline SPB & Simple Pay Back time & \multicolumn{2}{|l|}{ [y] } \\
\hline \multicolumn{4}{|c|}{ Greek symbols } \\
\hline$\alpha$ & \multicolumn{3}{|c|}{ specific emission factor of electricity } \\
\hline$\beta$ & \multicolumn{3}{|c|}{ the specific emission factor of natural gas } \\
\hline$\eta$ & \multicolumn{3}{|l|}{ efficiency } \\
\hline \multicolumn{4}{|c|}{ Subscript } \\
\hline aux & \multicolumn{3}{|l|}{ auxiliaries } \\
\hline av & \multicolumn{3}{|l|}{ avoided } \\
\hline B & \multicolumn{3}{|l|}{ boiler } \\
\hline chil & \multicolumn{3}{|l|}{ chiller } \\
\hline $\mathrm{CC}$ & \multicolumn{3}{|l|}{ cooling coil } \\
\hline co & \multicolumn{3}{|l|}{ cooling } \\
\hline EG & \multicolumn{3}{|l|}{ electric grid } \\
\hline el & \multicolumn{3}{|l|}{ electric } \\
\hline $\mathrm{HC}$ & \multicolumn{3}{|l|}{ heating coil } \\
\hline NG & \multicolumn{3}{|l|}{ natural gas } \\
\hline $\mathrm{p}$ & \multicolumn{3}{|l|}{ primary } \\
\hline $\mathrm{ph}$ & \multicolumn{3}{|l|}{ post-heating } \\
\hline reg & regeneration & & \\
\hline $\mathrm{SC}$ & solar collectors & & \\
\hline th & thermal & & \\
\hline us & final user & & \\
\hline Supersc & & & \\
\hline RS & Reference System & & \\
\hline SDCS & Solar Desiccant Cooling Sy & & \\
\hline Acronyt & & & \\
\hline $\mathrm{AHU}$ & Air Handling Unit & & \\
\hline $\mathrm{CC}$ & Cooling Coil & & \\
\hline CPVT & Concentrating Photovoltaic & & \\
\hline DCS & Desiccant Cooling System & & \\
\hline DHW & Domestic Hot Water & & \\
\hline DW & Desiccant Wheel & & \\
\hline $\mathrm{HC}$ & Heating Coil & & \\
\hline IHE & Internal Heat Exchanger & & \\
\hline
\end{tabular}


PVT Photovoltaic/Thermal

RS Reference System

SDCS Solar Desiccant Cooling System

\section{References and Notes}

1. G. Angrisani, C. Roselli, M. Sasso, Distributed microtrigeneration systems, Progress in Energy and Combustion Science 38 (2012) 502-521.

2. A. Khalid, M. Mahmood, M. Asif, T. Muneer, Solar assisted, pre-cooled hybrid desiccant cooling system for Pakistan, Renewable Energy 34 (2009) 151-157.

3. T.S. Ge, F. Ziegler, R.Z. Wang, H. Wang, Performance comparison between a solar driven rotary desiccant cooling system and conventional vapor compression system (performance study of desiccant cooling), Applied Thermal Engineering 30 (2010) 724-731.

4. K.F. Fong, C.K. Lee, T.T. Chow, Z. Lin, L.S. Chan, Solar hybrid air-conditioning system for high temperature cooling in subtropical city, Renewable Energy 35 (2010) 2439-2451.

5. F. Calise, M. Dentice d'Accadia, C. Roselli, M. Sasso, F. Tariello, Desiccant-based AHU interacting with a CPVT collector: Simulation of energy and environmental performance, Sol. Energy (2013), http://dx.doi.org/10.1016/j.solener.2013.11.001.

6. M. Beccali, P. Finocchiaro, B. Nocke, Energy and economic assessment of desiccant cooling systems coupled with single glazed air and hybrid PV/thermal solar collectors for applications in hot and humid climate, Solar Energy 83 (2009) 1828-1846.

7. Angrisani $G$ et al. Dynamic performance assessment of a micro-trigeneration system with a desiccant-based air handling unit in Southern Italy climatic conditions. Energy Conversion and Management 80 (2014) 188-201.

8. G. Angrisani, C. Roselli, M. Sasso, Experimental validation of constant efficiency models for the subsystems of an unconventional desiccant-based Air Handling Unit and investigation of its performance, Applied Thermal Engineering 33-34 (2012) 100-108.

9. RC Group, air-cooled water chiller model CILLI.IDROCOMPL.A.STD M.9.Z.1, http://www.rcgroup.ru/pdf/52576882.pdf [last accessed 16.02.2014].

10. K. F. Fong, T. T. Chow, Z. Lin, L. S. Chan, Simulation-optimization of solar-assisted desiccant cooling system for subtropical Hong Kong, Applied Thermal Engineering 30 (2010) 220-228.

11. Sigurd Helio Selec 202, www.sigurd.eu.com, technical data of flat-plate collectors.

12. Kloben solar collector mod. SKY 18 CPC 58, www.kloben.it, technical data of evacuated collectors.

13. Ministerial Decree of 28 December 2012, "Incentivazione della produzione di energia termica da impianti a fonti rinnovabili ed interventi di efficienza energetica di piccolo dimensioni”, 2012, http://www.gazzettaufficiale.it/atto/serie_generale/caricaDettaglioAtto/originario?atto.dataPubblic azioneGazzetta=2013-01-02\&atto.codiceRedazionale=12A13722 (in Italian).

(C) 2014 by the authors; licensee MDPI, Basel, Switzerland. This article is an open access article distributed under the terms and conditions of the Creative Commons Attribution license (http://creativecommons.org/licenses/by/3.0/). 